\title{
MATERNAL PSYCHOLOGY ON BREASTFEEDING TWINS: A SCOPING REVIEW
}

\author{
Mellysa Wulandari Tasripin, Herlin Fitriana K
}

Universitas ‘Aisyiyah Yogyakarta, Indonesia

\begin{abstract}
Background: Breastfeeding is the process of giving breast milk to infants from birth to 2 years of age. Breastfeeding twins requires more dedication than breastfeeding a single baby and there are many challenges in breastfeeding twins. This study aimed to review the psychological impact of mothers on breastfeeding twins.

Subjects and Methods: This study used a scoping review study by using the Arksey \& O'Malley framework. Article identification was using 4 databases, namely Pubmed, Wiley, Sciene Direct, and Ebsco from 2004 to 2019. Keywords selected related to this study and based on the criteria of inclusion are mothers who have twins, full text, in English and Indonesian. The data were reviewed using the Preferred Reporting Items For Systematic Reviews and Metaanalysis (PRISMA) flowchart guidelines.

Results: Nine articles were reviewed out of 1015 extracted. Nine of these articles were screened using the Joanna Briggs Institute. Articles were come from developed and developing countries. Based on the article, there were 2 themes, namely the psychological impact of mothers who breastfeed twins and the support provided by their families. The mother becomes stressed when caring for twins, feels physical exhaustion and the mother feels that the production of breast milk is not sufficient for the baby's needs. Husband or family support regarding care for newborns during breastfeeding, caring for older children, helping with household chores and encouraging or supporting mothers to continue breastfeeding.

Conclusion: The psychological impact that occurs in the mother of twins is that the mother feels stress and the support of her husband or family greatly influences the mother to overcome the psychology of the mother of twin babies.
\end{abstract}

Keywords: experience, breastfeeding, twins

Correspondence:

Mellysa Wulandari Tasripin. 'Aisyiyah University Yogyakarta. Jl. Siliwangi, Yogyakarta, Indonesia. Email: mellysamelz@gmail.com Mobile: 085223024257

The $7^{\text {th }}$ International Conference on Public Health

Solo, Indonesia, November 18-19, 2020 | 182

https://doi.org/10.26911/the7thicph.03.02 